\title{
Fracture features of dielectric nanoceramic with graphene by high-voltage discharge
}

\author{
Aleksandr Kuznetsov ${ }^{1}$, Georgii Savenkov ${ }^{* 1}$, and Vladimir Stolyarov ${ }^{2}$ \\ ${ }^{1}$ JSC "Armalit Mechanical Engineering Plant," 198097 St. Petersburg, Russia \\ ${ }^{2}$ Mechanical Engineering Research Institute of RAS, 101990, Moscow, Russia
}

\begin{abstract}
Results of dynamic strength investigation for $\mathrm{Al}_{2} \mathrm{O}_{3}$ nanoceramic with different content of five-layer flake graphene under action of nanosecond duration high-voltage pulse are given. It has been found that the graphene content increasing results in embrittlement of the nanocomposite during of nanosecond loading.
\end{abstract}

\section{Introduction}

Interest in nanostructured materials in fundamental-applied science and in industry is increasing. In many industries, cermet composites are widely used with greater strength but brittleness than metal materials. The solution to the problem of increasing the viscosity of composites can be the use of carbon nanoparticles of various types, including graphene (G) [1]. Composites with graphene have a number of unique electrophysical, mechanical and thermal properties [2-6]. Of particular interest is a composite based on aluminum nanopowder and small additives of multilayer graphene obtained by the SPS method [5].

The SPS method allows one to obtain a ceramic composite with a density close to the theoretical value and grain size close to the particle size of the initial powder. It is assumed that graphene flakes located at the grain boundaries of the ceramic matrix can cause a significant decrease in the fragility of the $\mathrm{Al}_{2} \mathrm{O}_{3}$ composite due to an increase in the adhesive properties of submicron elements [5]. Some works confirm this in bending tests under static compression [7]. However, there is practically no information on the features of the destruction of such compositions under extreme conditions of dynamic loading in the nanosecond region.

The aim of the work is to study the strength and fracture nature of the $\mathrm{Al}_{2} \mathrm{O}_{3} / \mathrm{G}$ nanocomposite with an increase in the graphene content under conditions of a high-voltage discharge.

\section{Experimental materials and methods}

A composite based on dielectric $\mathrm{Al}_{2} \mathrm{O}_{3}$ nanoceramic (particle size $45 \mathrm{~nm}$ ) with the content of conductive additives of five-layer flake graphene $0.5,1.5$, and $2.0 \mathrm{wt} . \%$ Was chosen as the studied material. The composite was obtained by mixing powders and subsequent sintering by the SPS method [7].

*Corresponding author:sav-georgij@yandex.ru 
The samples were disks with a diameter of $15 \mathrm{~mm}$ and a thickness of $2.5 \mathrm{~mm}$. The microhardness of the nanocomposite was measured on an FM-800 Future-Tech under a load of $300 \mathrm{~g}$ for $10 \mathrm{~s}$. The flexural strength to failure was determined on a Quasar 50 machine using methods for brittle materials [8].

To study the dynamic strength of a nanocomposite to destruction by a high-voltage discharge, we used the solid dielectrics destruction method under conditions of surface breakdown by nano- and submicrosecond durations [9], which is based on the discovery [10]. The general block-diagram of the experimental setup is shown in Fig. 1.

As a source of voltage pulses, a short-pulse generator GKVI-300 was used. The generator allows you to receive rectangular pulses with voltage $100-300 \mathrm{kV}$, duration 30 $300 \mathrm{~ns}$, current amplitude $2 \mathrm{kA}$ and energy $60 \mathrm{~kJ}$. The distance between the electrodes corresponded to the thickness of the samples.

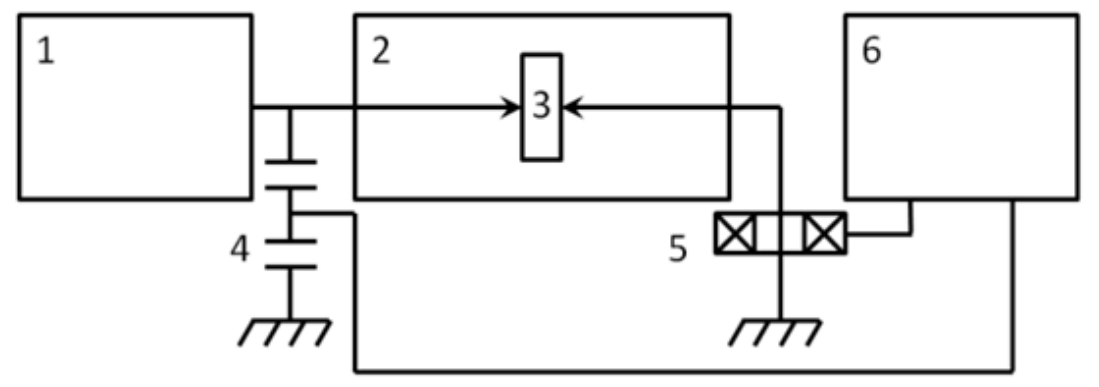

Fig. 1. Block-scheme of the experimental installation: 1 - generator, 2 - experimental camera with electrodes, 3 - sample, 4 - voltage meter, 5 - current meter, 6 - oscillograph.

In order to prevent breakdown on the sample surface, the destruction was carried out in a chamber filled with distilled water. In each experiment, a voltage pulse applied between the electrodes was monitored using a capacitive voltage divider, and the current passing through the sample was measured using a Rogowski belt. Signals from both devices were fed to a Tektronix TDS 2012 digital 2-channel oscilloscope.

The essence of electric-pulse destruction of disk samples is the formation of conducting plasma channels in the material, their expansion after they overlap the interelectrode gap, the generation of waves of predominantly tensile stresses and brittle cracking of the disk material [11]. Under single-pulse loading above the fracture threshold, the sample splits into two or more fragments. The closer to the fracture threshold, the fewer fragments and at the fracture threshold the number of fragments becomes equal to two.

The mechanical energy that directly goes to the destruction of the sample is part of the total electrical energy stored in the pulse generator, is determined by the relation [12]:

$$
E_{m}=K_{e m} E_{e l}
$$

where $k_{e m}=0.06-0.08$ is the coefficient of electrical energy conversion into mechanical energy. Electric energy is determined by the recorded waveforms of current and voltage.

\section{Results and discussion}

Microhardness and bending strength of composite ceramics are presented in table 1. It is seen that the microhardness of aluminum ceramics increases significantly with the use of 
$\mathrm{Al}_{2} \mathrm{O}_{3}$ nanopowder and the introduction of graphene. As for the bending strength, it decreases sharply when switching from a large-sized powder to a nanosized powder.

However, the introduction of graphene up to $2 \%$ can partially compensate for the decrease in bending strength.

Table 1. Microhardness and bending strength of pure and composite $\mathrm{Al}_{2} \mathrm{O}_{3}$ ceramics.

\begin{tabular}{|c|c|c|c|}
\hline $\begin{array}{c}\text { Powder } \\
\text { dispersity }\end{array}$ & $\begin{array}{c}\text { Graphene, } \\
\text { wt.\% }\end{array}$ & $\begin{array}{c}\text { Microhardness, } \\
\text { GPa }\end{array}$ & $\begin{array}{c}\text { Bending strength, } \\
\mathrm{MPa}\end{array}$ \\
\hline polycrystalline & 0 & $15.5[13]$ & $550[10]$ \\
\hline subcrystalline & 0 & $22.1[7]$ & $200[7]$ \\
\hline nanocrystalline & 2 & $27.4[7]$ & $260[7]$ \\
\hline
\end{tabular}

In Fig. 2 shows typical oscillograms of current and voltage during high-voltage breakdown of nanocomposites with different graphene contents.

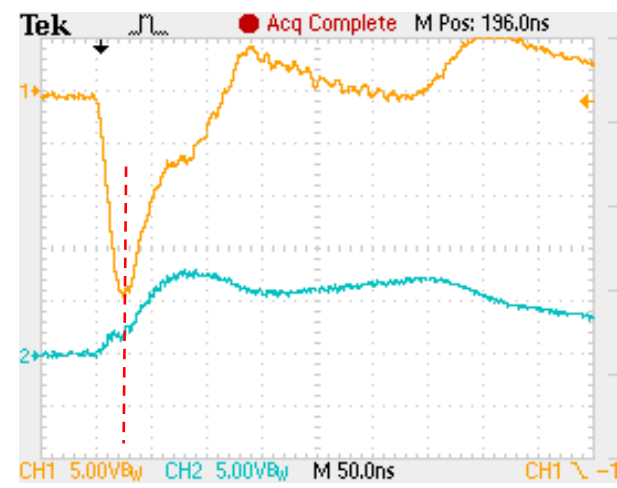

a

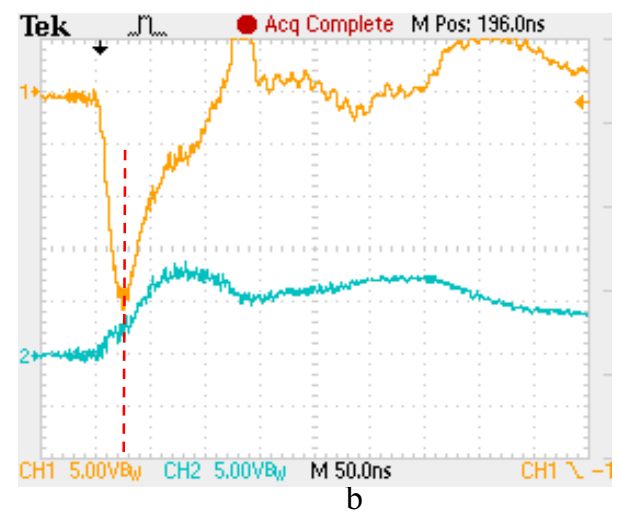

b

Fig. 2. Typical oscillograms of voltage (1) and current (2) pulses: a - Al2O3 + 0,5\% G; b - Al2O3 + $2,0 \% \mathrm{G}$. The dotted line marks the moment of electrical breakdown.

As the experiments showed, the breakdown voltage and the current at which it occurred turned out to be almost the same in all experiments, regardless of the graphene content. Since the thickness of the samples is quite small, their fragmentation took place far beyond the threshold of destruction. Therefore, the conditional criterion for the dynamic strength of the samples, which indicated the effect of graphene additives, was the number of fragments into which the sample was destroyed [14].

The constant value of the electrical breakdown is obviously due exclusively to the high power of the GKVI-300 voltage generator and the small thickness of the samples.

The number of fragments into which the samples were destroyed, depending on graphene content, significantly varied: at a content of $0.5 \%$ graphene, the number of fragments was $7-9$; at $1.5 \%-11-14$; at $2 \%-17-20$ (Fig.3). Only those fragments whose characteristic size was not less than $0.5 \mathrm{~mm}$ were counted. In this case, the mass deficit of the samples after their destruction was determined. In all cases, the mass deficit was not more than $1.5 \%$.
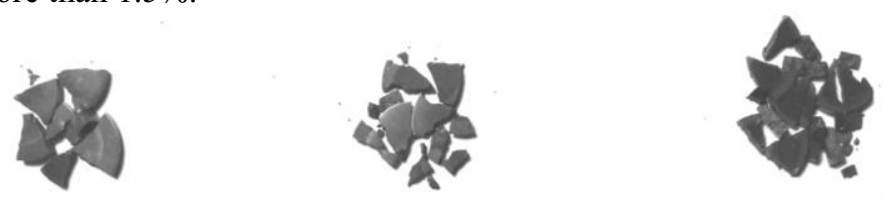

Fig.3. Fragments of the destroyed samples: from left to right $-0.5 \%, 1.5 \%, 2.0 \% \mathrm{G}$. 
Thus, with an increase in the graphene content, the number of fragments into which the samples are destroyed upon exposure to a high-voltage pulse increases sharply. The result obtained is consistent with the data of [15], in which the addition of copper oxide nanosized particles to the studied materials led to general embrittlement of the samples upon exposure to the products of an electric explosion of a conductor that was in the sample from an energy-storage phase material (paraffin or wax).

The results of the study showed that an increase in graphene content in the range of 0.5 $2.0 \mathrm{wt}$. \% contributes to an increase in the number of fragments upon destruction. A similar fact is typical for ceramics experiencing brittle fracture. Comparison of properties in Table 1 with the results of fragmentation during destruction also confirms this conclusion. Thus, the introduction of graphene into the nanocomposite sharply increases the microhardness, which generally indicates embrittlement of the material. In a nanocomposite, it is due to the inhibition of the formation of the main transcrystalline crack and its replacement by intergranular fracture.

The work has been supported by Russian Science Foundation [grant № 16-19-10213].

\section{References}

1. K. S. Novoselov, A.K. Geim, S. V. Morozov, D. Jiang, M. I. Katsnelson, I. V. Grigorieva, S. V. Dubonos, A. A. Firsov, Nature, 438, 197 (2005)

2. H. Xia, X. Zhang, Z. Shi, Z. Zhao et al., Y. Li J. Wang G. Qiao, Mater. Sci. Eng., 639, 29 (2015)

3. H. J. Kim, S.M. Lee, Y.S. Oh, Y.H. Yang, Y. S. Lim, D.H. Yoon, Ch. Lee, J.Y. Kim, R. S. Ruoff Sci. Rep., 2014, 4, 5176 (2014)

4. A. Centeno, V. G. Rocha, B. Alonso, A. Fernández, C. F. Gutierrez-Gonzalez, R. Torrecillas, A. Zurutuza, J. Eur. Ceram. Soc., 33, 201(2013)

5. A. Borrell, R. Torrecillas, V. G. Rocha, A. Fernández, V. Bonache, M. D. Salvador, Wear. 274, 94 (2012)

6. S. Stankovich, D. A. Dikin, G. H. B. Dommett, K. M. Kohlhaas, E. J. Jimney, E. A. Stach, R. D. Piner, S. T. Nguyen, R. S. Ruoff, Nature, 442, 282 (2006)

7. E. A. Klyatskina, A. Borrell, E. G. Grigoriev, A. G. Zholnin, M. D. Salvador, V. V. Stolyarov, J. Ceram. Sci. Technol., 9, 215 (2018)

8. A. T. Tumanov, M.: Mashinostroenie, 320 (1974) in Russian

9. A. F. Usov, Vestnik Kol'skogo nauchnogo tsentra RAN, 4, 166 (2012) in Russian

10. A. A. Vorobyov, G. A. Vorobyov, A.T. Chepikovet, Russian Discovery Certificate, A-122 (1998)

11. V. V. Lopatin, M. D. Noskov, G.Z. Usmanov, A.A. Cheglakov, Phys. Mesomechanics, 1389 (2010)

12. A. A. Lukin, V. A. Morozov, Yu.V. Sudyenkov, Bull. St. Petersburg State Uni. Ser. 2 , 133 (2008)

A. G. Zholnin, I. V. Kovaleva, M. S. Yurlova, A. M. Ilyina, E. G. Grigoriev, E. A. Olevsky, Phys. i Chim. Obr. Mater., 2, 73 (2015) in Russian

13. M. Michálek, M. Michálková, et al, Ceram. Inter. 44, 3255 (2018)

14. G. G. Savenkov, V. A. Morozov, A. A. Lukin, Tech. Phys. Lett., 42, 1110 (2016) 